\title{
A case of autoimmune hepatitis following pegylated interferon treatment of chronic hepatitis delta
}

\author{
(D) Feruze Enc, (1) Celal Ulasoglu \\ Department of Gastroenterology, Istanbul Medeniyet University, Goztepe Training and Research Hospital, Istanbul, Turkey
}

\begin{abstract}
Autoimmune hepatitis may be frequently associated with chronic hepatitis $\mathrm{C}$ (HCV) infection, but there are few case reports regarding hepatitis $B$ and Delta infection ( $\mathrm{HBV}+\mathrm{HDV}$ ) as possible triggers. In this report, we present a 44 years old man who was diagnosed as autoimmune hepatitis (AIH) following the treatment of HBV+HDV hepatitis with pegylated interferon (PegIFN). He presented with complaint of fatigue. Laboratory indicated elevated liver enzymes, AST 64IU/L and ALT 112 IU/L. The results revealed HBsAg and anti-delta antibody positivity. HBV-DNA was $<31.6 \mathrm{IU} / \mathrm{mL}$ and HDV-RNA $487.300 \mathrm{copy} / \mathrm{mL}$. Peg-IFN was initiated for 96 weeks. Without a serious adverse effect, the enzymes regressed to normal within 24 weeks. After 96 weeks of treatment, there was a three-fold increase in aminotransferases, with no cholestasis. Immunoglobulin-G (IgG) was $3686 \mathrm{mg} / \mathrm{dL}$ (reference 540-1822 mg/dL), anti-smooth muscle antibody (ASMA) and anti-nuclear antibody (ANA) were positive. The liver biopsy had all diagnostic clues for AIH. Methylprednisolone and azathioprine treatment was initiated with tenofovir (TdF) prophylaxis. Due to unresponsiveness, even with doubling the dosage for immunosuppressives, treatment was stopped and shifted to mycophenolate mofetil. The patient responded in the $6^{\text {th }}$ month and still under treatment with TdF and mycophenolate mofetil with normal enzymes and negative HDV RNA.
\end{abstract}

Keywords: Autoimmune hepatitis; chronic hepatitis delta; interferon.

Cite this article as: Enc F, Ulasoglu C. A case of autoimmune hepatitis following pegylated interferon treatment of chronic hepatitis delta. North Clin Istanb 2020;7(4):407-410.

A utoimmune hepatitis (AIH) is an uncommon, chronic liver inflammation with an unclear etiology [1]. AIH is characterized by fluctuating alanine aminotransferase (ALT) levels in serum, marked hypergammaglobulinemia and circulating organ and non-organ specific autoantibodies [2,3]. Like most of the autoimmune diseases, AIH is predominant in females with a prevalence of less than $0.02 \%[1,2]$. In genetically predisposed individuals, exposure to environmental factors triggers the autoimmune cascade. Infections (e.g., HBV, HCV, HDV, HAV and HSV), medications (nitrofurantoin, hydralazine, methyldopa, alpha and beta interferon, infliximab and etanercept) and toxins are some of the possible triggering factors.
Here, we present a male patient who gave informed consent for this case report was diagnosed as AIH after pegylated interferon (pegIFN) treatment of the chronic delta hepatitis.

\section{CASE REPORT}

A 44-year-old male patient with no past medical history presented to our hospital with a complaint of generalized weakness. The patient had no history of abdominal pain, nausea, vomiting, pruritus, illicit or herbal drug use, skin tattoos, blood transfusions, alcohol abuse, acetaminophen use, recent travel or multiple sexual partners and also any known liver disease. Phys-

Received: March 25, 2019 Accepted: July 01, 2019 Online: May 28, 2020

Correspondence: Feruze ENC, MD. Medeniyet Universitesi, Goztepe Egitim ve Arastirma Hastanesi, Gastroenteroloji Klinigi, PK 34722 Kadikoy, Istanbul, Turkey.

Tel: +90544 4322878 e-mail: feruzey@yahoo.com

(c) Copyright 2020 by Istanbul Provincial Directorate of Health - Available online at www.northclinist.com 

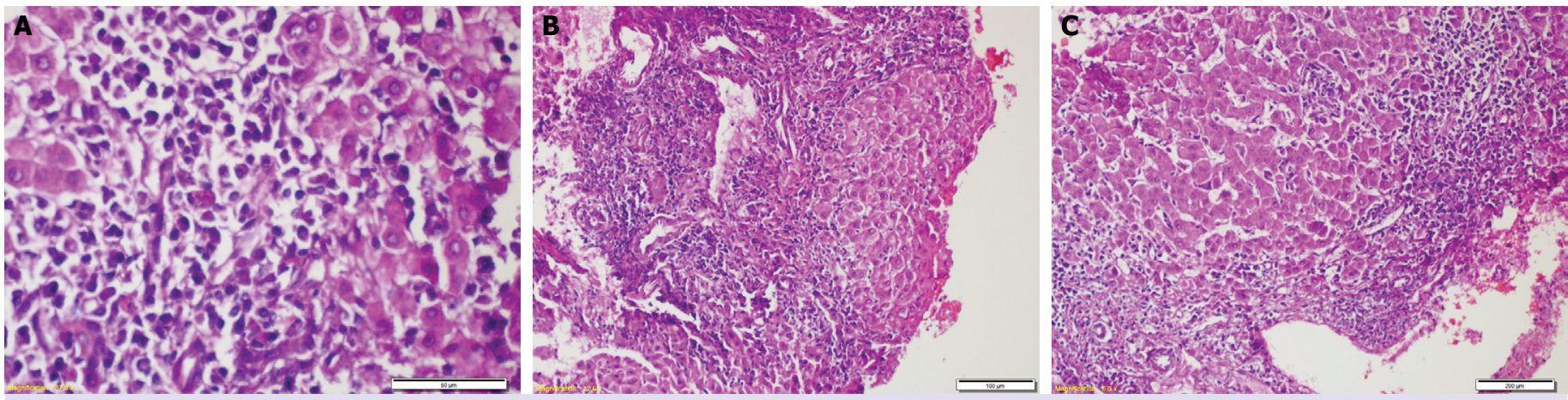

FIGURE 1. (A) Hematoxylin-eosin stain (high power) indicating rosette formation and emperipolesis. (B) Hematoxylin-eosin stain (low power) portal and adjacent parenchyma having lymphoplasmacytic infiltrate, representing interface hepatitis. (C) Hematoxylin-eosin stain (low power) focal necrosis in the parenchyma.

ical examination was completely normal and the Kayser-Fleischer ring was not found. Laboratory findings were significant for elevated liver enzymes; AST 64 $\mathrm{IU} / \mathrm{L}, \mathrm{ALT} 112 \mathrm{IU} / \mathrm{L}$, total bilirubin $0,78 \mathrm{mg} / \mathrm{dL}$ and AFP 2,49 ng/mL (reference $<9 \mathrm{ng} / \mathrm{mL}$ ). Other laboratory parameters were normal. A thorough workup was done for differential diagnosis of elevated liver enzymes. Viral serology showed $\mathrm{HBsAg}(+), \mathrm{HBeAg}(-)$, AntiHBe (+), AntiHBs (-), HBVDNA: <31.6 IU/ $\mathrm{mL}$, Anti-HIV (-) and Anti-HCV (-). The Anti-Delta antibody was positive and the HDV-RNA PCR level was $487.300 \mathrm{copy} / \mathrm{mL}$. Hepatobiliary ultrasonography was normal. Liver biopsy revealed histology activity index as $6 / 18$ and fibrosis index as $1 / 6$ (ISHAK). Peg-IFN alpha 2a $180 \mathrm{mcg} /$ week treatment was introduced to the patient. There were no remarkable side effects related to peg-IFN. His AST and ALT levels regressed to normal during the treatment period, and HDV RNA became negative. During follow-up, the third month after the end of treatment, transaminases were found as AST $113 \mathrm{IU} / \mathrm{L}$ and ALT $261 \mathrm{IU} / \mathrm{L}$. In extended laboratory examinations, total protein 8.8 $\mathrm{g} / \mathrm{dL}$, albumin $3.8 \mathrm{~g} / \mathrm{dL}$ were detected. Thus, autoimmune hepatitis was suspected. Anti-nuclear antibody (ANA) was homogenously positive at $1 / 100$ titer, anti-smooth muscle antibody (ASMA) positive at $1 / 160$ level. Anti-mitochondrial (AMA), liver-kidney microsomal (LKM) and soluble liver antigen (SLA) antibodies were negative. Immunoglobulin $\mathrm{G}$ was $3686 \mathrm{mg} / \mathrm{dL}$ (reference $540-1822 \mathrm{mg} / \mathrm{dL}$ ), HBsAg positive, $\mathrm{HBV}$ DNA $<31.6 \mathrm{IU} / \mathrm{mL}$ and HDV RNA (-) and cholestatic enzymes were normal. The biopsy was performed and demonstrated autoimmune hepatitis with findings of excessive lymphoplasmacytic infiltration at portal area extending into lobule (interface hepatitis), emperipolesis, rosette formation and focal parenchymal necrosis (Fig. 1). According to International Autoimmune Hepatitis Group (IAHG) scoring system calculating parameters as alkaline phosphatase/ALT ratio, IgG level, autoantibodies, viral serology, drug usage, alcohol consumption, histological details and presence of other autoimmune disease the patient had a score of 13 , indicating "probable autoimmune hepatitis". The history and clinical features excluded drug-induced liver injury. Tenofovir prophylaxis was started one month before azathioprine and methylprednisolone therapy. In his follow-up, AST, ALT, IgG elevation were persisted, and the dosage of immunosuppressive drug was doubled. After 24 weeks, there was no biochemical response, so the treatment was replaced with mycophenolate mofetil as $1000 \mathrm{mg}$ bid. With this protocol, the transaminases, IgG levels gradually came to normal at the end of 24 weeks of therapy. Due to the lack of any autoimmunity evidence until the initiation of treatment, pegylated interferon seems to be related to resulting autoimmune hepatitis in this patient.

\section{DISCUSSION}

The pathophysiology of autoimmune hepatitis is still not fully understood, but clues of environmental and individual triggering factors on genetic predisposition may play a crucial role. Untreated cases gradually progress to liver cirrhosis and eventually may lead to liver failure and rarely hepatocellular carcinoma [4]. There are classically three types of AIH based on serologic findings. Recently, Type 3 is regarded within Type 1. The serological positivity of ASMA and ANA is ac- 
cepted as Type $1 \mathrm{AIH}$. Type $2 \mathrm{AIH}$ is mostly seen in the pediatric age group; anti-liver kidney microsome-1 (anti-LKM-1) and anti-liver cytosol type 1 antibody (anti-LC-1) are present. The presence of these autoantibodies is not mandatory for diagnosis and approximately $10-30 \%$ of the patients are negative for autoantibodies [5]. In our patient, ASMA and ANA positivity, liver biopsy findings, elevated transaminases and increased IgG level were highly suggestive of AIH emerging on chronic $\mathrm{HBV}+\mathrm{HDV}$ co-infection after peg-IFN therapy.

Hepatotropic viruses are reported as triggering agents that initiate autoimmune diseases. Especially, $\mathrm{HCV}$ is frequently reported as a relevant factor [5]. Even though the mechanism is not fully explained, the development of AIH in chronic viral hepatitis patients may be related to mimicry of shared protein antigens of virus and hepatocyte membrane antigens [6].

It is proposed that low viral load may correlate with low suppressor T-cell activity, while B-cell activation results with auto-antibody production [6]. Antigen-presenting cells (APC) and major histocompatibility complex (MHC) interaction lead to induce inflammatory cytokines release [7].

Hepatitis D virus is a defective RNA agent which is dependent on HBV for continuing its life cycle. Peg-IFN is the treatment of choice in chronic HDV infection besides entry inhibitors, farnesyl transferase inhibitors, immunotherapy (betaglyceramide, DNA vaccines, AntiHB immune complexes), clevudine, siRNA (small interfering RNA), TLR agonists, PD1 +PD L1 (programmed death protein+ligand) and eventually orthotopic liver transplantation (OLTx). As a known smallest infectious agent, HDV is a cytopathic virus and liver injury is not due to the immunological process [8].

Besides infectious agents, chemicals and drugs may also provoke genesis of AIH. Peg-IFN, as an immunomodulatory drug, may also trigger autoimmunity affecting different organs, such as liver, thyroid, and dermis [9]. Autoimmune disorders are observed in $4-19 \%$ of patients receiving interferon-alpha and interferon-induced autoimmune hepatitis during treatment has been observed in approximately $25-40 \%$ of the HBV patients, which is unusual in HCV patients [10]. In our patient treatment with pegylated interferon-alpha seems as the main trigger for this autoimmune activation since there was no evidence of auto- immunity before treatment. Ongoing studies are on the way to establish monitoring HDV RNA titer as surrogate marker and treatments without pegylated interferon-alpha, for example, entry inhibitors to hepatocyte (myrcludex B), inhibitors of farnesyl transferase (lonafarnib), lambda interferon and nucleic acid inhibitors (REP $2139 \mathrm{Ca})[11,12]$.

As a conclusion, the elevation of transaminases should remind the possibility of a new emerging autoimmune hepatitis, which may be triggered by viral agents (HBV, HCV, HDV), drugs (interferon) or maybe a de novo autoimmune hepatitis.

Informed Consent: Written informed consent was obtained from the patient for the publication of the case report and the accompanying images.

Conflict of Interest: No conflict of interest was declared by the authors.

Financial Disclosure: The authors declared that this study has received no financial support.

Authorship Contributions: Concept - FE; Design - FE; Supervision - CU; Fundings - CU; Materials - FE; Data collection and/ or processing - CU; Analysis and/or interpretation - CU; Literature review - CU; Writing - FE; Critical review - CU.

\section{REFERENCES}

1. Shoenfeld Y, Levin N, Noel R. Infection and Autoimmunity. $2^{\text {nd }}$ ed. Rose Academic Press; 2015. [CrossRef]

2. Sostre V, Patel HG, Mohamed A, Volfson A. A Case of Acute Autoimmune Hepatitis Superimposed on Chronic Hepatitis B Infection. Case Rep Gastrointest Med 2018;2018:2139607. [CrossRef]

3. Czaja AJ, Carpenter HA, Santrach PJ, Moore SB, Taswell HF, Homburger HA. Evidence against hepatitis viruses as important causes of severe autoimmune hepatitis in the United States. J Hepatol 1993;18:342-52. [CrossRef]

4. Gatselis NK, Zachou K, Koukoulis GK, Dalekos GN. Autoimmune hepatitis, one disease with many faces: etiopathogenetic, clinico-laboratory and histological characteristics. World J Gastroenterol 2015;21:60-83. [CrossRef]

5. European Association for the Study of the Liver. EASL Clinical Practice Guidelines: Autoimmune hepatitis. J Hepatol 2015;63:971-1004.

6. Laskus T, Slusarczyk J. Autoimmune chronic active hepatitis developing after acute type B hepatitis. Dig Dis Sci 1989;34:1294-7. [CrossRef]

7. McFarlane IG. Immunological abnormalities and hepatotropic viral infections. Clin Exp Immunol 1992;87:337-9. [CrossRef]

8. Negro F. Hepatitis D virus coinfection and superinfection. Cold Spring Harb Perspect Med 2014;4:a021550. [CrossRef]

9. Amarapurkar DN. Flares on and off therapy during chronic HBV infection: Pathogenesis, significance and management. Hep B Annual 2008;5:12-22. [CrossRef]

10. Rathi C, Pipaliya N, Choksi D, Parikh P, Ingle M, Sawant P. Autoimmune Hepatitis Triggered by Treatment With Pegylated Inter- 
feron $\alpha-2 \mathrm{a}$ and Ribavirin for Chronic Hepatitis C. ACG Case Rep J 2015;2:247-9. [CrossRef]

11. Yurdaydin C, Abbas Z, Buti M, Cornberg M, Esteban R, Etzion O, et al; Hepatitis Delta International Network (HDIN). Treating chronic hepatitis delta: The need for surrogate markers of treatment efficacy. J Hepatol 2019;70:1008-15. [CrossRef]

12. Yurdaydin C. New treatment options for delta virus: Is a cure in sight? J Viral Hepat 2019;26:618-26. [CrossRef] 